\title{
What the future may hold?
}

\author{
Ian Yeoman ${ }^{1}$
}

Published online: 29 June 2018

(C) Macmillan Publishers Ltd., part of Springer Nature 2018

Revenue Management and pricing faces many challenges moving into the future and one of the purposes of this journal is to address those challenges, issues, and changes. Marketing managers are often in a dilemma about which pricing index to rely on while calculating the annual increase in the prices for their product. Topuz and colleagues examined producer and consumer prices in two ways, first the supply and demand relationship. Second, by using data from two different countries. According to the results of the impulse-response analysis and variance decomposition, producer prices are relatively more effective on the consumer prices in both countries. The results provide important insights for pricing decision makers in firms. Pricing managers can now consider the producerlevel inflation to be the lead indicator for consumer-level inflation.

Ozhegova and Ozhegov model demand of Russian theatre performances that accounts for heterogeneity in price and product characteristics effects, also taking into consideration seat quality and position. The study reveals a strong link between price elasticity and attendance quantile. An important feature of the research is that the perception of quality for the same seat may vary with the production type because seats with better view of the stage are valued more on ballets while closer to the stage seats with better quality of sound are valued more on operas.

Hermel and Mantin consider a profit-maximizing seller who encounters consumers over two periods. The contribution of the paper lies in extending the theory of Revenue Management in the presence of strategic consumers. The

Ian Yeoman

ian.yeoman@vuw.ac.nz

1 Victoria University of Wellington, Wellington, New Zealand authors contribute that a capacity-constrained retailer can be better off facing consumers who behave strategically rather than myopically. $\mathrm{Ng}$ and colleagues examine the impact of daily deals from web channel where suppliers offer promotions, with deals varying in their terms and conditions (Ts and Cs), their popularity with customers, and the revenue they generate on rate fences in restaurants. Findings include that restrictions did not always negatively impact deal outcomes. Time restrictions, new customer restrictions, and shorter redemption period had positive associations with deal outcomes. This statement contradicts previous research based upon the ideal deal that has fewer restrictions. Instead, the use of restrictions may make the deal seem more special and thus more appealing. Abdul's paper focuses on consumers' price fairness perception of past purchase in situations of price reduction of innovative consumer durables. The contribution lies in the findings of this study in post-purchase evaluations by providing explanation for post-purchase evaluation based on often neglected attribute of price.

Oancea and Horga practitioners' perspective advances the position that travel technology as well as the fierce competition that will continue in the following years will redefine not only the way people perceive the travel experience and the way it is distributed, but also the way airlines will price their products and manage their revenues. Oancea discusses what makes a Pricing and Revenue Management professional a great performer and in what way is the future different than the one of today. Vieveen's short article explores how restaurant Revenue Management is currently managed in full-service restaurants and what the future may hold? 